\title{
Why We Still Need To Speak About Sex Differences and Sex Hormones in Pain
}

\author{
Anna Maria Aloisi
}

Received: July 4, 2017 / Published online: October 20, 2017

(c) The Author(s) 2017. This article is an open access publication

\section{ABSTRACT}

In the world of pain, we must always consider the presence of gender. In nociception, as well as in pain, women are different from men in many, if not all, aspects of the system. Nociception is the sum of several events that occur from the periphery to the CNS, and there is much evidence that female nociception differs from male nociception. Moreover, it has to be considered that pain results from a male or a female cortex. Genetic, anatomical, physiological, hormonal, psychological, and social factors have been considered to explain the differences present at both levels. Notwithstanding all the evidence, it is still difficult to observe the application of this knowledge to the treatment of pain. Drugs are still given per kilogram, and clinical studies, albeit including women, often mix data from both sexes. Moreover, reports on these studies often fail to mention the women's age and reproductive status, i.e., sex hormones. Hormone levels vary from hour to hour, from day to day, and, as repeatedly confirmed, are affected by several pain killers commonly used

Enhanced content To view enhanced content for this article go to http://www.medengine.com/Redeem/ 37CCF0603306019A.

A. M. Aloisi $(\square)$

Dipartimento Scienze Mediche, Chirurgiche e

Neuroscienze, Università di Siena, Siena, Italy

e-mail: annamaria.aloisi@unisi.it in pain therapy. All the data confirm the urgent need to include sex differences and sex hormones among the key factors that play an important role in pain and pain treatment.

Keywords: Gonadal hormones; Pain; Sex differences

\section{EDITORIAL}

Pain is divided into acute and chronic. Acute pain is an alarm system able to preserve the individual's health status. Chronic pain is an illness that may be disconnected from the original pathology and without any meaning for the subject. Sex differences have been found in both conditions.

Acute experimental pain, in which the painful stimulus is short-lasting and the threshold and tolerance are the studied parameters, often presents sex differences depending on the painful stimulus used to test the patient, with women being equally or more affected than men [1].

Chronic pain is not one pathology but hundreds. Chronic pain can affect all parts of the body, with different features related to the quality, intensity, time course, and clinical outcome. These pathologies include many chronic painful syndromes that are more common in women, while others are more common 
in men and others still have a similar incidence in the two sexes [2]. This simple evidence suggests that there is no common pathophysiological sex-related mechanism underlying all painful conditions; any one condition is modulated by factors that could differ between men and women.

It is known that when pain is related to a clinical condition that can be painful (e.g., diabetes) the incidence is due to the primary pathology. Interestingly, also in this case it is quite difficult to find studies regarding the relative incidence of pain in the different diseases; e.g., given the same number of diabetic patients, is pain more common in men or women?

To explain the higher incidence in women in some chronic painful syndromes, it has been hypothesized that the female anatomical features, mostly related to pelvic organs, could play an important role [3]. The female bladder is much more exposed to external pathogens than the male bladder on account of the shorter urethral tract and the vagina connecting the external environment directly with the interior of the pelvis. The colon could be inflamed-irritable bowel syndrome (IBS) and other forms of colitis are more common in women [4].

All these conditions can be painful per se or merely able to lower the threshold of other painful conditions. Indeed they are often present at the subclinical level and subjects are not aware of the inflammation processes occurring in one or more pelvic viscera; pain, if present, is often referred to other parts of the soma, e.g., to the back.

Sex hormones are important modulators of body functions. We know their role in reproduction, but often we forget that androgen and estrogen have receptors in almost all cells of our body; their action can be rapid or slow but in any case it can be important for the functioning of many systems, including nociception/pain.

Only recently, attention has been focused on the action of sex hormones on pain modulation and in particular on the immune system. For instance, microglia, the resident immune cells in the CNS, play a critical role (different in men and women) in the pathogenesis of chronic pain, particularly in the development of central sensitization and neuropathic pain [5]. Of course, sex differences in microglia are just one aspect of the broader male-female differences in the immune system.

Another important interaction between sex hormones and the pain system regards the endogenous and/or exogenous opioid system. The arcuate nucleus of the hypothalamus is the main site of $\beta$-endorphin production. Its axons end in the periaqueductal gray matter (PAG) where the release of $\beta$-endorphin is able to activate the descending inhibitory pathways. The $\beta$-endorphin neurons in the arcuate nucleus are strongly modulated by estrogens [6]. Furthermore, many studies have reported that the spinal $\delta$ and $\kappa$ opioid antinociceptive systems are functionally associated with estrogens. In particular, estrogen receptors regulate synthesis and secretion of the $\delta$ opioid receptor ligand methionin-enkephalin in addition to the well-known regulation of $\beta$-endorphin content and secretion [7].

In an interesting experiment, male and female mice used to replicate a model of neuropathic pain showed that the two sexes react differently to structural and functional changes induced by sciatic nerve ligature. While the male mice showed a gradual decrease of allodynia and a complete recovery from the injury, in the female mice the allodynia and gliosis were still present 4 months after induction of neuropathy. Estrogen supplementation was able to attenuate this difference, reducing the allodynia and inducing a complete recovery also in the female mice [8].

Thus, although estrogens are clearly involved in pain modulation, their role is still not clear. Estrogens remain a complex "world"-from the great difficulty in measuring them to their complex hypothalamic-pituitary modulation, their enzymatic production (aromatase enzyme and others), and their complex receptor system (both at the cytoplasm and membrane levels) [9]. For all these reasons, it took a long time to realize that estrogen administration to experimental animals could induce opposite results depending on many factors, a major one being the concentration. In pain modulation, all kinds of results were found: to summarize we can say that low 
estrogen concentrations generally have a pronociceptive action while higher concentrations can have an important analgesic effect, as occurs during pregnancy [10].

In conclusion, these few experimental results explain the need to maintain the focus on sex differences in pain and on sex hormones, since they are powerful molecules able to influence all the cells of our body. Their multi-target interaction with CNS functions allows continuous reciprocal modulation. Mood, arousal, learning, and memory are all modulated by sex hormones directly and/or indirectly, e.g., through the immune system; these processes are all involved in pain modulation.

Therefore, hormonal fluctuations due to reproductive cycles, life events, and pharmacological treatments are important. This variability can be significant, i.e., it can improve or worsen body conditions, but it is important to consider that these changes can also be induced artificially. Sex hormones, like all hormones, can be given or blocked: why not do this for pain?

\section{ACKNOWLEDGEMENTS}

This study was supported from the University of Siena. No funding or sponsorship was received for the publication of this article. The named author meets the International Committee of Medical Journal Editors (ICMJE) criteria for authorship for this manuscript, takes responsibility for the integrity of the work as a whole, and has given final approval for the version to be published.

Disclosures. Anna Maria Aloisi has nothing to disclose.

Compliance with Ethics Guidelines. This article is based on previously conducted studies and does not involve any new studies of human or animal subjects performed by any of the authors.

Open Access. This article is distributed under the terms of the Creative Commons
Attribution-NonCommercial 4.0 International License (http://creativecommons.org/licenses/ by-nc/4.0/), which permits any noncommercial use, distribution, and reproduction in any medium, provided you give appropriate credit to the original author(s) and the source, provide a link to the Creative Commons license, and indicate if changes were made.

\section{REFERENCES}

1. Pieretti S, Di Giannuario A, Di Giovannandrea R, et al. Gender differences in pain and its relief. Ann Ist Super Sanita. 2016;52(2):184-9. doi:10.4415/ ANN_16_02_09.

2. Sorge RE, Totsch SK. Sex differences in pain. J Neurosci Res. 2017;95(6):1271-81. doi:10.1002/jnr. 23841.

3. Stratton P, Berkley KJ. Chronic pelvic pain and endometriosis: translational evidence of the relationship and implications. Hum Reprod Update. 2011;17(3):327-46. doi:10.1093/humupd/dmq050.

4. Houghton LA, Heitkemper M, Crowell M, et al. Age, gender and women's health and the patient. Gastroenterology. 2016;. doi:10.1053/j.gastro.2016.02. 017.

5. Mapplebeck JC, Beggs S, Salter MW. Molecules in pain and sex: a developing story. Mol Brain. 2017;10(1):9. doi:10.1186/s13041-017-0289-8.

6. Pluchino N, Ninni F, Casarosa E, et al. Sex differences in brain and plasma beta-endorphin content following testosterone, dihydrotestosterone and estradiol administration to gonadectomized rats. Neuroendocrinology. 2009;89(4):411-23. doi:10. $1159 / 000209506$.

7. Gintzler AR, Schnell SA, Gupta DS, Liu NJ, Wessendorf MW. Relationship of spinal dynorphin neurons to delta-opioid receptors and estrogen receptor alpha: anatomical basis for ovarian sex steroid opioid antinociception. J Pharmacol Exp Ther. 2008;326(3):725-31. doi:10.1124/jpet.108. 139816.

8. Vacca V, Marinelli S, Pieroni L, Urbani A, Luvisetto S, Pavone F. 17beta-estradiol counteracts neuropathic pain: a behavioural, immunohistochemical, and proteomic investigation on sex-related differences in mice. Sci Rep. 2016;8(6):18980. doi:10. 1038/srep18980. 
9. Aloisi AM, Sorda G. Relationship of female sex hormones with pain perception: focus on estrogens. Pain Manag. 2011;1(3):229-38. doi:10.2217/ pmt.11.13.

10. Smith YR, Stohler CS, Nichols TE, Bueller JA, Koeppe RA, Zubieta JK. Pronociceptive and antinociceptive effects of estradiol through endogenous opioid neurotransmission in women. J Neurosci. 2006;26(21):5777-85. 